\title{
Studying the effect of vortex finder eccentricity on the gas cyclone performance
}

\author{
Shimaa Helmy ${ }^{1}{ }^{*}$, Khairy Elsayed ${ }^{1}$, Momtaz Fahmy Sedrak ${ }^{1}$ \\ ${ }^{1}$ Mechanical Power Engineering Department, Faculty of Engineering at El-Mattaria, \\ Helwan University, Masaken El-Helmia P.O., Cairo 11718, Egypt.
}

\begin{abstract}
In this study, cyclone separator, with nine different vortex finder eccentricities are simulated computationally (CFD). The numerical technique is based upon solving three dimensional, incompressible, turbulent flow governing equations using the Reynolds stress turbulent model. The results show that moving the vortex finder eccentricities in two directions is more effective than moving it in one direction only. Case 5 achieves the lowest pressure drop where the vortex finder eccentricity is moved in the positive $\mathrm{x}$ and $\mathrm{y}$ directions toward the cyclone inlet. It is found that moving the eccentricities in both $\mathrm{x}$, $\mathrm{y}$ directions towards the cyclone inlet reduces the pressure drops by $31 \%$ and decreases the collection efficiency by $17.4 \%$ compared to case 0 (where the vortex finder is concentric in the cyclone centerline).
\end{abstract}

\section{Keywords:}

Cyclone separators, Computational fluid dynamics (CFD), Reynolds stress model (RSM), Discrete phase modeling (DPM), Vortex finder eccentricity.

\section{Nomenclature}

$\begin{array}{ll}a & \text { Cyclone inlet height }[\mathrm{m}] \\ \mathrm{B}_{\mathrm{c}} & \text { Cyclone cone-tip diameter }[\mathrm{m}] \\ \mathrm{b} & \text { Cyclone inlet width }[\mathrm{m}] \\ \mathrm{d}_{\mathrm{p}} & \text { Particle diameter }[\mathrm{m}] \\ \mathrm{D} & \text { Cyclone body diameter }[\mathrm{m}]\end{array}$




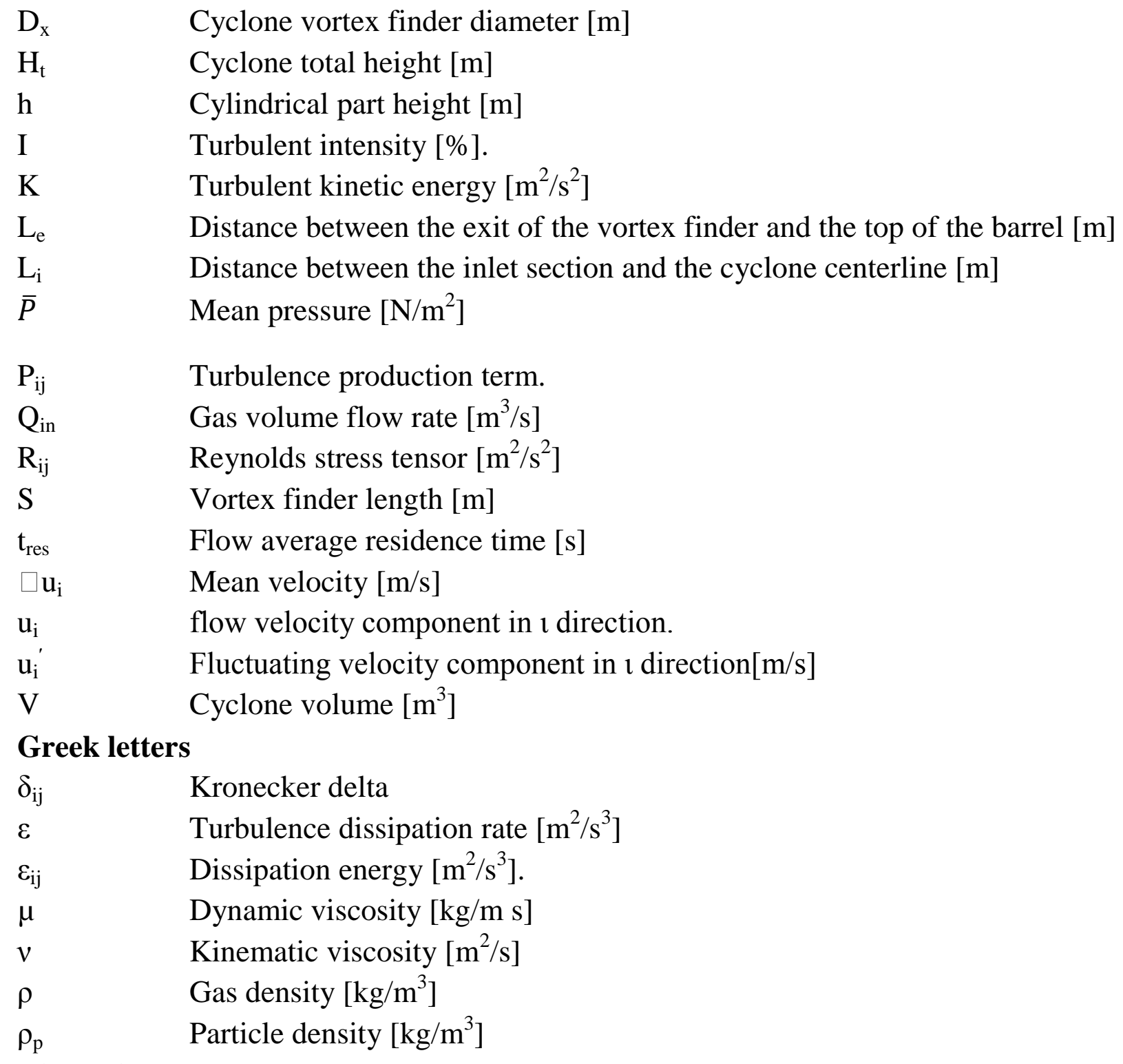

\section{Dimensionless numbers}

$\mathrm{C}_{\mathrm{D}} \quad$ Particle drag coefficient

$\mathrm{Eu} \quad$ Euler number

Re Reynolds number

$\mathrm{S}_{\mathrm{g}} \quad$ Geometrical swirl number
Abbreviations
CFD
Computational Fluid Dynamics
DPM Discrete Phase Modeling
LDA Laser Doppler Anemometry
LES Large Eddy Simulation.
PIV Particle Image Velocimetry
RANS Reynolds Average Navier-Stokes
RSM Reynolds Stress Model 


\section{Introduction}

Cyclone separator is a popular particle separator device that is widely used to separate phases with different densities. Cyclone consists of two main parts, an upper cylindrical part and a lower conical part. Its simple construction, low operating, maintenance cost and its ability to sustain high pressure and temperature gain it the privilege to participate in different industrial and engineering application such as a catalytic converter, vacuum cleaner, etc....

The tangential inlet and the rounded shape of the cyclone body generate the swirling motion which creates centrifugal force that pushes the particles away toward the cyclone wall where they spiral in the downward direction forming an outer free vortex. When the flow hits the bottom surface, the particles settle down while the cleaned gas reverses its direction in an inner spiral motion (forced vortex) and escapes through the exit pipe (vortex finder) as show in Fig. 1.
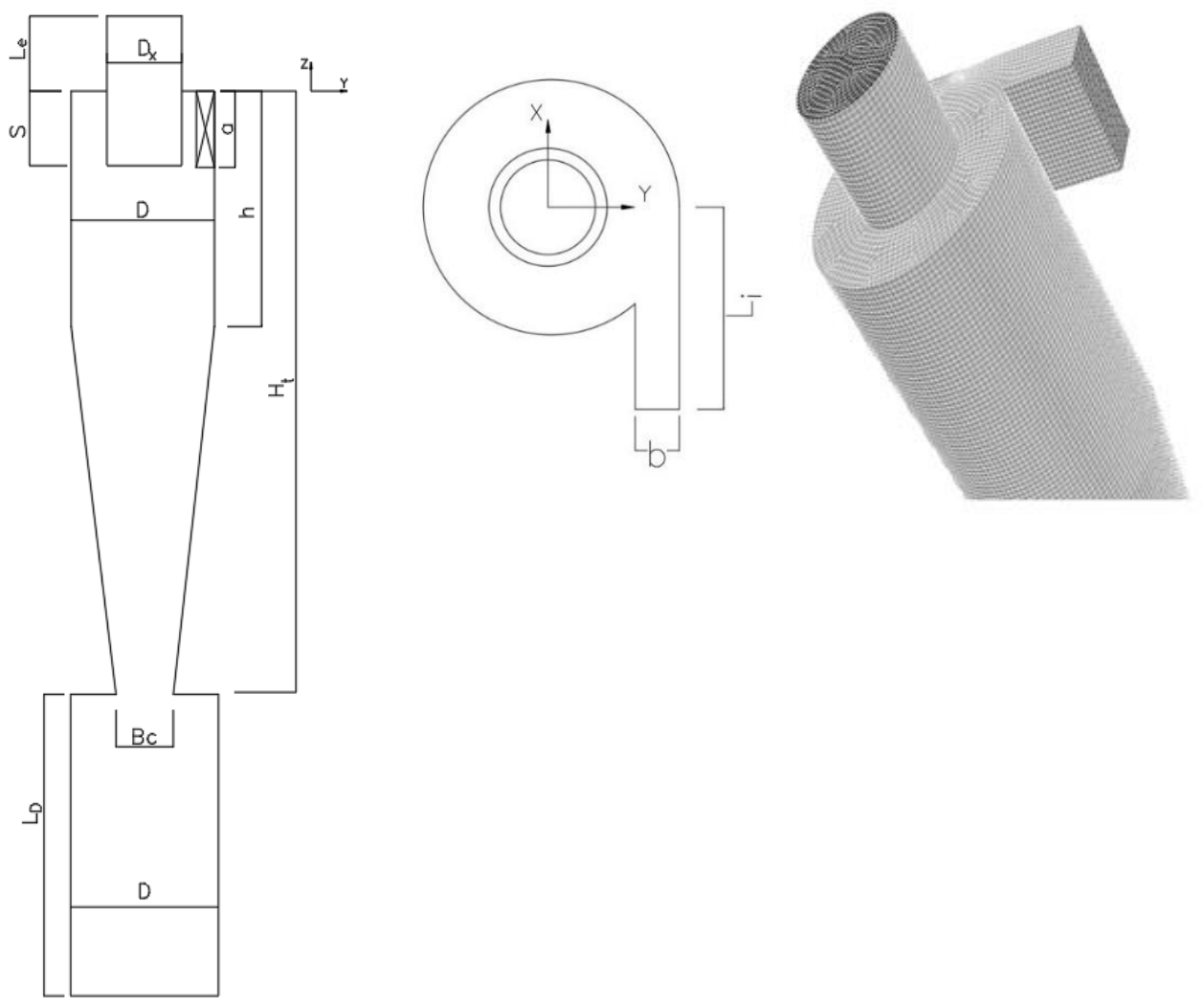

Figure 1 : Geometrical configuration of cyclone and mesh

The flow inside the cyclone follows what is called Rankine vortex. Although of its simple construction and working principle the flow inside the cyclone is extremely complicated (high swirl, isothermal, three-dimensional, turbulent flow). It is worth 
to mention that swirl and turbulence are considered the two competing phenomena behind the separation process inside the cyclone. Swirl induces a centrifugal force on the solid particles while turbulence disperses the particles and improves its ability to get caught and collected in the dustbin (Elsayed and Lacor, 2011).

There are two main design criteria used to evaluate the cyclone performance, namely, the pressure drop and the collection efficiency. Several papers tried to enhance the cyclone performance via minimizing the pressure drop and increasing the collection efficiency. The collection efficiency is used to measure the particle separation. The overall separation efficiency is the mass of the collected particles divided by the total injected mass. The grad efficiency is the separation efficiency calculated for a specific particle size. The pressure drop is a measure of the energy consumption. It is related to the cyclone operating cost.

The literature divided the factors that affect the cyclone performance into: geometrical parameters (as shown in Fig. 1), particle properties, gas properties and some other factors such as wall roughness, shape and eccentricities of the vortex finder.

Elsayed and Lacor (2011 a) computationally studied the effect of the inlet dimensions on the cyclone performance. The results showed that increasing the cyclone inlet dimension decreases both the pressure drop and the collection efficiency, and indicate that the optimum ratio is obtained if inlet width to inlet height ratio is between 0.5 and 0.7. Dere et al. (2014) also emphasized the significant role of the inlet dimension on cyclone performance.

Chuah et al. (2006) computationally studied the effect of the cone tip diameter on the cyclone performance; the results showed that decreasing the cone tip diameter increases the collection efficiency and pressure drop.

Elsayed and Lacor (2011 b) computationally studied the effect of the dust collector, the results reported the insignificant role of the dust collector on the cyclone performance. In another study Elsayed and Lacor (2012) computationally studied the effect of four different dust outlet geometries on the accuracy of the computational results, the results declared that although removing the dustbin will save large effort in computational time, it affects the accuracy of the results, $10 \%$ error in Euler number and 35\% in the cut-off diameter results in cyclone without dustbin. Dere et al. (2014) emphasized the insignificant role of the cone tip diameter.

Liu et al. (2015) numerically investigated the effect of the cone tip diameter $\left(\mathrm{B}_{\mathrm{c}}\right)$ on the cyclone performance, the result showed that increasing the ratio of the cone 
tip diameter to the cyclone body diameter (D) increases the cyclone pressure drop. This is due to increase the contacting area between the particles and the wall which increases the friction loss. The optimum ratio was obtained at $B_{c} / D=0.355$ which achieved the highest collection efficiency with a relatively small pressure drop.

Karagoz and Avci (2005) introduced a mathematical model to calculate the pressure drop across the cyclone separators. The results declared that the pressure drop inside the cyclone separator depends on the cyclone geometry, the mass loading and the operation conditions. The results also emphasized that increasing the inlet temperature decreases the pressure drop.

Elsayed and Lacor (2010) computationally studied, by using the Reynolds stress model and the response surface methodology, the effect of different geometrical parameters on the cyclone pressure drop. The results revealed an optimized model which achieved half the pressure drop with respect to the Stairmand high efficiency design. This study also emphasized the capability of the Reynolds stress turbulent model to capture the flow phenomena inside the cyclone in a better matching with the experimental results.

Pravaz et al. (2018) computationally studied the effect of the inner cone on pressure drop and the erosion rate, the results reported that increasing the height and diameter of the inner cone reduce the cyclone pressure drop. The conventional cyclone has higher erosion rate compared to the cyclone with the inner cone.

Elsayed and Lacor (2011c) via numerous studies arranged the most significant parameters affecting the cyclone performance into: the vortex finder diameter, the inlet width, the inlet height and the cyclone total height respectively.

Kim and Lee (1990) experimentally studied the effect of the exit tube size. The results showed that as the exit pipe diameter decreases the collection efficiency increases and vice versa. As the exit pipe increases to a certain extent, the pressure drop decreases. The minimum value for the pressure drop achieved at a ratio of exit body diameter to the cyclone body diameter $\left(\mathrm{D}_{\mathrm{e}} / \mathrm{D}\right)$ between 0.5 and 0.6.

Elsayed and Lacor (2010) computationally studied the effect of the vortex finder diameter on the collection efficiency and the pressure drop. The results showed that decreasing the vortex finder diameter increases the collection efficiency but at the cost of increasing the pressure drop.

Brar et al. (2015) computationally studied the effect of the vortex finder diameter on the cyclone performance. They reported that increasing the vortex finder 
diameter reduces the cyclone pressure drop and decreases the collection efficiency and vice versa. They declared that the effect of the vortex finder diameter on the pressure drop is higher than that on the collection efficiency.

Zhu and Lee (1999) experimentally explored the effect of the vortex finder length (S). The results emphasized that the pressure drop decreases with decreasing the vortex finder length. The optimum design is achieved at a ratio of $((\mathrm{h}-\mathrm{S}) / \mathrm{D})=1$.

Cernecky and Plandorova (2012) computationally studied the effect of the vortex finder length $(\mathrm{S})$ on collection efficiency and pressure drop. Their results reported that increase the vortex finder length $(\mathrm{S})$ increase both the collection efficiency and pressure drop. Decreasing the vortex finder length decreases the collection efficiency as some particle directly escaped with the exit gas.

Lim et al. (2004) experimentally studied the effect of the vortex finder shape (four cylindrical shapes with different diameter and six cone shapes with different length) on the collection efficiency. The results showed that the collection efficiency of the cone shape vortex finder is higher than a cylindrical shape with a larger diameter $(15 \mathrm{~mm}$ diameter) and lower than that of smaller one $(7 \mathrm{~mm}$ diameter). The results also emphasized that the collection efficiency increases as the vortex finder diameter decreases. The cone shape has a larger effect on the collection efficiency compared to the cone length.

El Batsh (2013) computationally studied the effect of the exit pipe diameter and the length on the cyclone performance. The results declared that increasing the exit pipe diameter decreases the pressure drop on the other hand the exit pipe length has an insignificant effect on the cyclone performance.

Elsayed and Lacor (2013) computationally studied the effect of the vortex finder dimensions on the flow pattern and performance. The results showed that the vortex finder diameter has a significant effect compared to the vortex finder length, as decreasing the vortex finder diameter by $40 \%$, increases the cyclone pressure drop by $175 \%$. Whereas doubling the vortex finder length increases the pressure drop by $25 \%$.

Funk (2015) experimentally studied the effect of changing the vortex finder shape on the cyclone performance by adding rectangular and radial evases on the exit pipe outlet section. The results showed that adding radial evases reduces the cyclone pressure drop by 8.7 to $11.9 \%$. This reduction in the pressure drop reduces the electricity consumption and can achieve an investment up to 5 to 7 months return per year. 
Parvaz et al. (2017) computationally studied the effect of eccentricities of the vortex finder with ratios between 4 to $10 \%$ (the movement was on $\mathrm{x}$-direction only) on the cyclone performance. The results showed that increasing the eccentricity has an adverse effect on the cyclone performance (increase the

pressure drop and decrease the separation efficiency). The cyclone with $8 \%$ eccentricities was more efficient for particle greater than $1 \mu \mathrm{m}$ as it has the highest axial velocity while increasing the eccentricity to $10 \%$ reduces the downstream flow velocities which results in decreasing the collection efficiency.

Brar and Elsayed (2018) computationally studied the effect of the eccentric outlet pipe with respect to the cyclone centerline by using LES, the results were then optimized by using artificial neural network and genetic algorithms to choose the best eccentric location according to the required cyclone performance.

It is clear from all the previous studies, that there are numerous studies on the effect of the geometrical parameters including the vortex finder diameter and length however the effect of the vortex finder eccentricities still largely unexplored and need more investigation. Hereby this study aims to computationally study the effect of the vortex finder eccentricities on the flow pattern and cyclone performance in terms of the pressure drop and the collection efficiency.

\section{Numerical setting}

Numerical simulation for any given CFD problem consists of three basic steps: discretization of the fluid domain, solver setting and post processing.

The numerical setting is based upon solving the governing equations for three dimensional, incompressible, turbulent flow inside the cyclone separator.

\subsection{Governing equations}

The flow in cyclone is isothermal, incompressible, turbulent flow with high Reynolds number; for such flow (unsteady, incompressible, with constant temperature) the continuity equation and Reynolds average Navier-stokes equation can be written as:

$$
\begin{gathered}
\frac{\partial \bar{u}_{i}}{\partial x_{i}}=\mathbf{0}, \frac{\partial u_{i}^{\prime}}{\partial x_{i}}=\mathbf{0} \\
\frac{\partial \bar{u}_{i}}{\partial x_{t}}+\overline{\boldsymbol{u}}_{\boldsymbol{J}} \frac{\partial \bar{u}_{i}}{\partial x_{j}}=-\frac{1}{\rho} \frac{\overline{\partial P}}{\partial x_{i}}+v \frac{\partial^{2} \bar{u}_{\iota}}{\partial x_{j} \partial x_{j}}-\frac{\partial}{\partial x_{j}}\left(\overline{u_{\imath}^{\prime} \boldsymbol{u}_{\jmath}^{\prime}}\right)
\end{gathered}
$$

where $\bar{u}_{l}$,is the average velocity in i direction, $\bar{P}$ is the mean pressure, $\mathrm{x}_{\mathrm{i}}$ is the position in i direction, $v$ is the gas kinematic viscosity, $\rho$ is the gas density and 
$\overline{u_{\imath}^{\prime} u_{\jmath}^{\prime}}$ represent the Reynolds stress tensor $\left(\mathrm{R}_{\mathrm{ij}}\right)$. $\mathrm{u}_{\mathrm{i}}^{\prime}$ is the fluctuating velocity component.

\subsection{Selection of the turbulence model}

In spite of the cyclone simple construction, the flow inside the cyclone separator is highly swirling, turbulent flow. There are several turbulent models in Fluent that are capable in dealing with turbulent flow, however choosing the most appropriate one to deal with such turbulent flow consider one of the key parameters to reach a successful CFD simulation.

Several previous studies emphasis the capability of the Reynolds stress turbulent model (RSM) and the large eddy simulation (LES) to describe the turbulent phenomena of the combined vortex inside the cyclone separator and give accurate results that is compatible with the experimental data (Elsayed and Lacor, 2011).

The Reynolds stress turbulent model is capable to solve the transport equation for the Reynolds stress tensor together with an equation for the turbulent dissipation rate $\mathcal{E}$ as follow:

The RSM equation is given by:

$$
\begin{aligned}
& \frac{\partial}{\partial t} R_{i j}+\overline{u_{k}} \frac{\partial}{\partial x_{k}} R_{i j}=\frac{\partial}{\partial x_{k}}\left(\frac{\nu_{t}}{\sigma^{k}} \frac{\partial}{\partial x_{k}} R_{i j}\right)-\left[R_{i k} \frac{\partial \bar{u}_{j}}{\partial x_{k}}+R_{j k} \frac{\partial \bar{u}_{i}}{\partial x_{k}}\right] \\
& -C_{1} \frac{\varepsilon}{k}\left[R_{i j}-\frac{2}{3} \delta_{i j} K\right]-C_{2}\left[P_{i j}-\frac{2}{3} \delta_{i j} P\right]-\frac{2}{3} \delta_{i j} \varepsilon
\end{aligned}
$$

where $\mathrm{P}_{\mathrm{ij}}$ is the turbulent production $P_{i j}=\left[R_{i k} \frac{\partial \bar{u}_{j}}{\partial x_{k}}+R_{j k} \frac{\partial \bar{u}_{l}}{\partial x_{k}}\right], \mathrm{P}$ is the fluctuating kinetic energy production $\left(\mathrm{P}=1 / 2 \mathrm{P}_{\mathrm{ij}}\right), v_{\mathrm{t}}$ is the turbulence kinetic viscosity, $\sigma^{\mathrm{k}}, \mathrm{C}_{1}$, $\mathrm{C}_{2}$ are empirical constant that are used in the simulation and are equal 1, 1.8, 0.6 respectively and $\mathrm{K}$ is the fluctuating kinetic energy $\left(\mathrm{k}=\frac{1}{2} \overline{u_{\imath}^{\prime} u_{\imath}^{\prime}}\right)$.

The transport equation for RSM

$$
\boldsymbol{u}_{k} \frac{\partial}{\partial x_{k}}\left(\overline{\left.u_{\imath}^{\prime} \boldsymbol{u}_{j}^{\prime}\right)}=D_{i j}+\boldsymbol{P}_{i j}+\boldsymbol{\theta}_{i j}+\varepsilon_{i j}\right.
$$

where $D_{i j}$ represents the diffusion term, $P_{i j}$ is the stress generation term, $\theta_{i j}$ is the pressure strain correlation and $\varepsilon_{\mathrm{ij}}$ is the dissipation term. The interested reader can refer to Elsayed and Lacor (2011), Brar et al, (2015), Paravaz et al, (2017) for more details. 
In the current study, the Reynolds stress turbulent model (RSM) is used to investigate the effect of the vortex finder eccentricities on the cyclone performance and give a detailed view of the flow pattern inside the cyclone separator.

\subsection{CFD Grid and boundary condition}

The hexahedral computational grid were generated using Gambit grid generator, structured mesh type as shown in Figure (1) and the simulations were performed using Ansys Fluent 17.2 finite volume solver on an intel core i7 6700 HQ CPU, windows 10 operating system 64 bit. Two levels of grids namely 593 125, 744563 hexahedral cell are used as given in Table (1). The maximum difference in the result is less than 5\%, so the grid with 593125 hexahedral cells is consider good enough to produce grid independent results.

Table (1): The details of the grid independence study for cyclone $(0,0)$ eccentricities

\begin{tabular}{|l|c|c|}
\hline Total No. of cell & $\begin{array}{l}\text { Static pressure drop } \\
\text { (pa) }\end{array}$ & Euler No. \\
\hline 593125 & 1131.3 & 5.66 \\
\hline 744563 & 1134.6 & 5.67 \\
\hline Difference \% & 0.29 & 0.18 \\
\hline
\end{tabular}

A velocity inlet boundary condition is used for the inlet boundary with a uniform velocity magnitude of $20 \mathrm{~m} / \mathrm{s}$. The turbulent intensity $\mathrm{I}=5 \%$ which is expressed as:

$$
I=0.16\left(R e_{D_{h}}\right)^{-\frac{1}{8}}
$$

where $\operatorname{Re}_{\mathrm{Dh}}$ represent Reynolds number based on the hydraulic diameter) and the length scale is equal to 0.07 of the inlet width $=2.87 \mathrm{E}-3 \mathrm{~m}$. The velocity distribution at the inlet is assumed to be uniform.

The air flow rate $Q_{\text {in }}=84 \mathrm{l} / \mathrm{s}$, the air density $=1 \mathrm{~kg} / \mathrm{m}^{3}$ and the dynamic viscosity $\mu$ $=2.11 \mathrm{E}-5 \mathrm{~Pa} . \mathrm{S}$. The Reynolds number is $1.387 \times 10^{4}$ based on the inlet velocity and the hydraulic diameter. An outflow boundary condition is specified for the outlet boundary and a wall (no slip) boundary condition is used for all the other boundaries. 
At the cyclone inlet, the Reynolds stress specific method in the Fluent solver is the Reynolds stress components, the diagonal component of the Reynolds stress tensor (normal stresses) are assigned to $2 / 3 \mathrm{k}_{\text {in }}$, where $\mathrm{k}_{\text {in }}$ is the kinetic energy at the inlet and is equal $\left(3 / 2 \mathrm{I} \mathrm{U}_{\mathrm{in}}{ }^{2}\right)$, the shear stress at the inlet is set to zero. The standard wall function is used for the near wall treatment. The standard wall function gives reasonable predictions for the majority of high-Reynolds number wall-bounded flows.

\subsection{Configuration of the nine cyclone with different vortex finder eccentricities}

The numerical simulation on this study was concluded using nine cyclones with different vortex finder eccentricities $\left(e_{x}, e_{y}\right)$. The cyclone geometry is described by seven main geometrical parameters which are the inlet height (a), the inlet width (b), the vortex finder diameter $\left(D_{x}\right)$, the vortex finder length $(S)$, the cylindrical height $(\mathrm{h})$, the cyclone total height $\left(\mathrm{H}_{\mathrm{t}}\right)$ and the cone tip diameter $\left(\mathrm{B}_{\mathrm{c}}\right)$.

Table 2: Geometrical parameters for the cyclone configuration

\begin{tabular}{|l|l|l|l|l|l|l|l|}
\hline Dimension & $\begin{array}{l}\text { Inlet } \\
\text { height } \\
(\mathbf{a})\end{array}$ & $\begin{array}{l}\text { Inlet } \\
\text { width } \\
(\mathbf{b})\end{array}$ & $\begin{array}{l}\text { Vortex } \\
\text { finder } \\
\text { diameter } \\
\left(\mathbf{D}_{\mathbf{x}}\right)\end{array}$ & $\begin{array}{l}\text { Vortex } \\
\text { finder } \\
\text { length } \\
(\mathbf{S})\end{array}$ & $\begin{array}{l}\text { Total } \\
\text { height } \\
\left(\mathbf{H}_{\mathbf{t}}\right)\end{array}$ & $\begin{array}{l}\text { Cylindrical } \\
\text { height } \\
(\mathbf{h})\end{array}$ & $\begin{array}{l}\text { Cone tip } \\
\text { diameter } \\
\left(\mathbf{B}_{\mathbf{c}}\right)\end{array}$ \\
\hline $\begin{array}{l}\text { Dimensional } \\
\text { ratio }\end{array}$ & 0.5 & 0.2 & 0.5 & 0.5 & 4 & 1.5 & 0.375 \\
\hline Value (m) & 0.1025 & 0.041 & 0.1025 & 0.1025 & 0.82 & 0.3075 & 0.07688 \\
\hline
\end{tabular}

Dimensional ratio $=$ dimension / cyclone body diameter, Cyclone body diameter used in the current simulation $=0.205 \mathrm{~m}$. Dustbin length $\mathrm{L}_{\mathrm{D}}=2 \mathrm{D}=0.410 \mathrm{~m}$, dustbin diameter $=\mathrm{D}=0.205 \mathrm{~m}$, Inlet duct length $\mathrm{L}_{\mathrm{i}}=0.75 \mathrm{D}=0.15375 \mathrm{~m}$ and exit pipe length above the cylinder $\mathrm{L}_{\mathrm{e}}=0.5 \mathrm{D}=0.1025 \mathrm{~m}$.

Table 2 and Figure 1 declare the basic dimensions of the cyclone separator based on the Stairmand high efficiency model (where all the geometrical parameters are represented as a ratio to the cyclone body diameter, D). Figure 2 and Table 3 illustrate the different vortex finder eccentricities used in the current study.

\subsection{Selection of the time step}

The time step should be taken as a tiny fraction of the average residence time $\left(t_{\text {res }}\right)$. The average residence time is the time taken by the flow to pass through the whole computational domain, and it can be calculated as $t_{r e s}=\frac{V}{Q_{\text {in }}}$ where $\mathrm{V}$ is the cyclone volume $=3.346256 \mathrm{E}-02\left(\mathrm{~m}^{3}\right)$ and $\mathrm{Q}_{\text {in }}$ is the air flow rate $=0.084\left(\mathrm{~m}^{3} / \mathrm{s}\right)$ 
therefore $t_{r e s}=0.398 \mathrm{~s}$. So the time step of $1 \mathrm{E}-4$ considers suitable value to obtain an accurate result.

\subsection{Numerical schemes}

The simulation started with an unsteady simulation, pressure based solver using an implicit coupled solution algorithm and Reynolds stress turbulent model. The selection of the suitable discretization schemes has been tested by many researchers. Paravaz et al. (2017), Brar et al. (2015), Elsayed and Lacor (2012) and Karagoz and Avci (2008) recommended the schemes listed in Table (4) as they give the best matches with the experimental results. 
Case 0

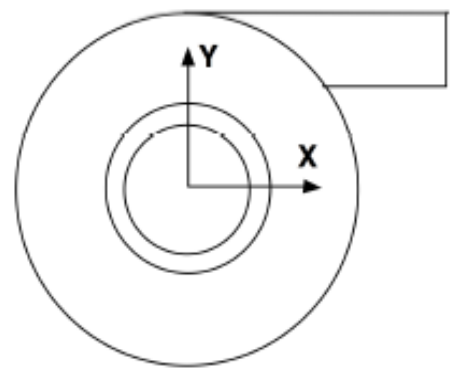

$(0.0,0.0)$

Case 3

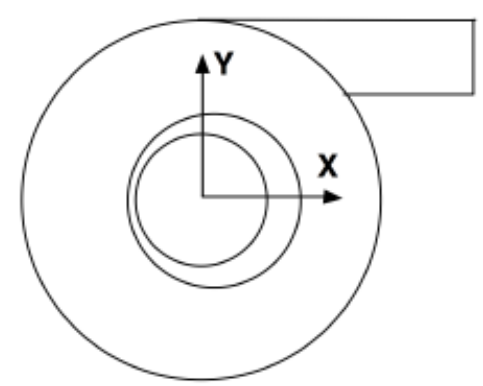

$(0.0625,0.0)$

Case 6

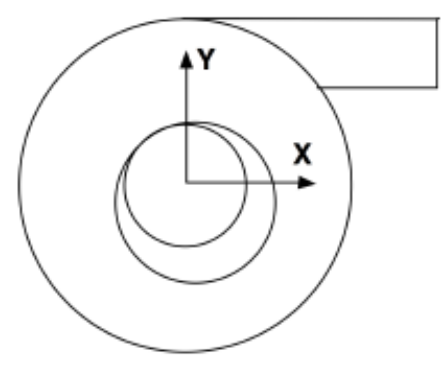

$(0.0625,-0.125)$
Case 1

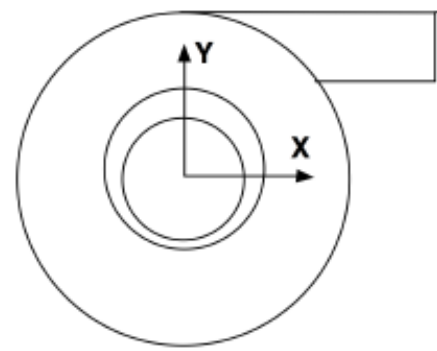

$(0.0,0.0625)$

Case 4

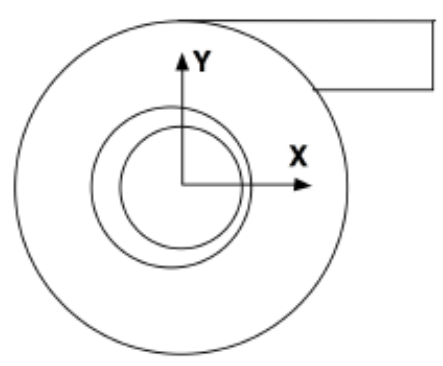

$(-0.0625,0.0)$

Case 7

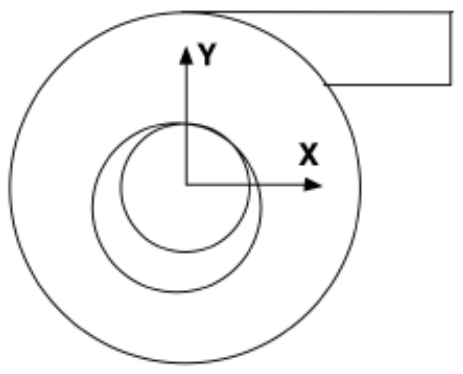

$(-0.0625,-0.125)$
Case 2

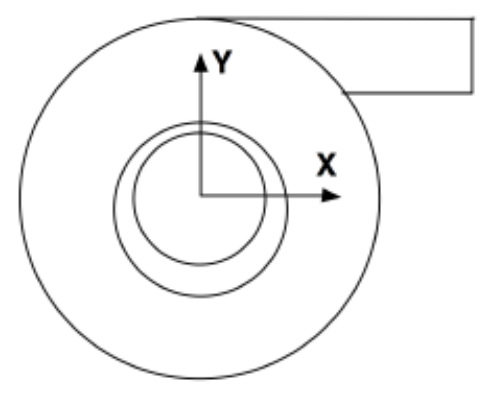

$(0.0,-0.0625)$

Case 5

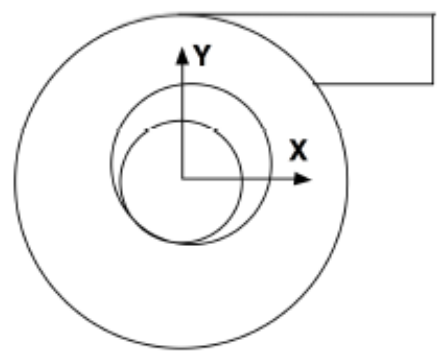

$(0.0625,0.125)$

Case 8

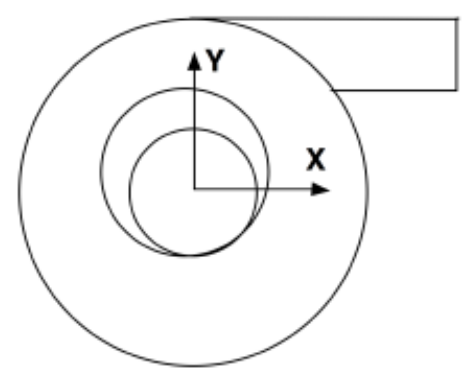

$(-0.0625,0.125)$

Figure 2: Plan view for the position of different vortex finder eccentricities 
Table 3: The position of different vortex finder eccentricities

\begin{tabular}{|c|c|c|c|}
\hline Cases & $\boldsymbol{e}_{\boldsymbol{x}}$ & $\boldsymbol{e}_{\boldsymbol{y}}$ & Illustrating drawing \\
\hline Case 0 & 0.0 & 0.0 \\
\hline Case 1 & 0.0 & 0.0625 \\
\hline Case 2 & 0.0 & -0.0625 \\
\hline Case 3 & 0.0625 & 0.0 \\
\hline Case 4 & -0.0625 & 0.0 \\
\hline Case 5 & 0.0625 & 0.125 \\
\hline Case 6 & 0.0625 & -0.125 \\
\hline Case 7 & -0.0625 & -0.125 \\
\hline Case 8 & -0.0625 & 0.125 \\
\hline
\end{tabular}

Note: the eccentric of the new vortex finder position represented by $\left(e_{x}=\frac{\Delta x}{R}, e_{y}=\frac{\Delta y}{R}\right)$ where $R$ is the cyclone radius, $\Delta \mathrm{x}, \Delta \mathrm{Y}$ are the difference between the new position and the original one (cyclone without eccentricity).

Table (4): The discretization scheme for the current simulations

\begin{tabular}{|c|c|c|c|c|c|c|c|}
\hline $\begin{array}{l}\text { Numerical } \\
\text { setting }\end{array}$ & $\begin{array}{l}\text { Pressure } \\
\text { velocity } \\
\text { coupling }\end{array}$ & $\begin{array}{l}\text { Pressure } \\
\text { discretization }\end{array}$ & $\begin{array}{l}\text { Momentum } \\
\text { discretization }\end{array}$ & $\begin{array}{l}\text { Turbulent } \\
\text { kinetic } \\
\text { energy }\end{array}$ & $\begin{array}{l}\text { Turbulent } \\
\text { dissipation } \\
\text { rate }\end{array}$ & $\begin{array}{l}\text { Reynold } \\
\text { s stress }\end{array}$ & $\begin{array}{l}\text { Transient } \\
\text { formulation }\end{array}$ \\
\hline $\begin{array}{l}\text { Discretization } \\
\text { scheme }\end{array}$ & 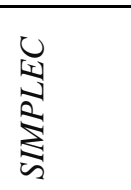 & $\begin{array}{l}0 \\
\frac{1}{2} \\
\frac{1}{2} \\
2\end{array}$ & 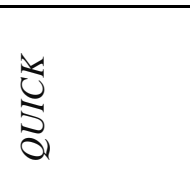 & 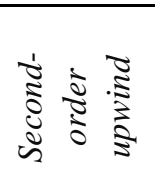 & 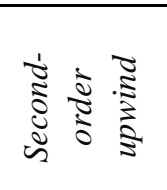 & 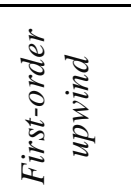 & 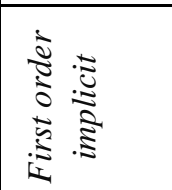 \\
\hline
\end{tabular}

\section{Validation of the numerical model}

In order to verify the accuracy of the numerical model, it is necessary to compare the predicted results with an experimental measurement. Comparison was made between the current simulation and Hoekstra (2000) using Laser doppler anemometry (LDA) based on the Stairmand high efficiency design at axial station located at $\mathrm{Z}=0.75 \mathrm{D}=1076.25 \mathrm{~mm}$ measured from the cyclone bottom. It is clear from Fig. 3 that the simulation result matches the experimental result with an underestimation near the cyclone wall and a tiny overestimation in the central core. 


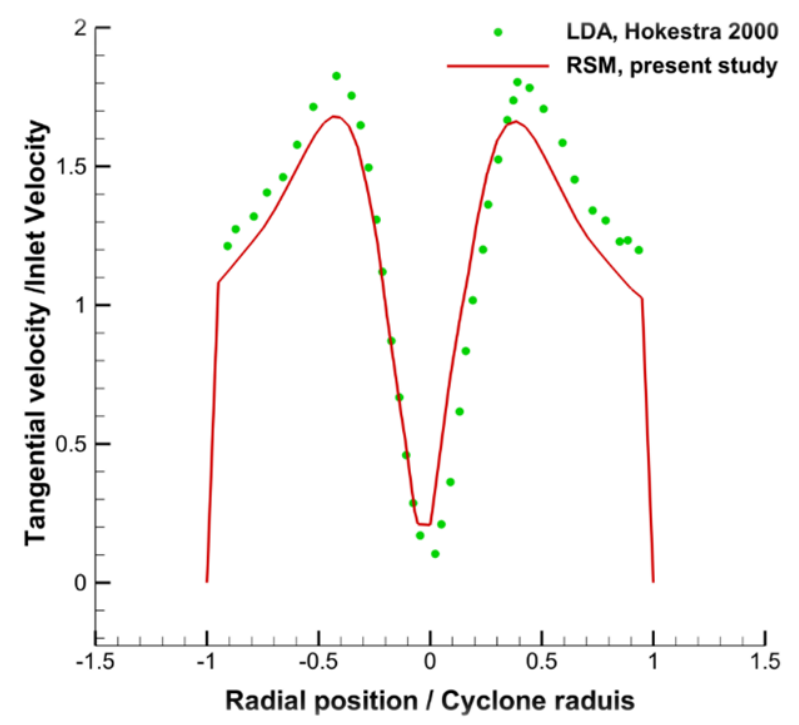

Figure 3: Validation of the time average tangential velocity with experimental data.

Regarding the complexity of the turbulent flow inside the cyclone, the match between the simulated and experimental results is considered quite acceptable.

\section{Results and discussion}

The flow velocity can be resolved into three velocity components; tangential, axial and radial. The radial velocity is small compared with the other two velocity components in cyclone separator. The tangential velocity is the main source for the centrifugal force that results in the particle separation, while the axial velocity is responsible for the upward and downward flow streams inside the cyclone.

The velocity profiles inside the cyclone are plotted at nine different sections as shown in Table (5). Figure 4 represents a comparison between the radial profile for the time average static pressure, tangential and axial velocities at the nine different sections for case (0) and case (3) where the vortex finder eccentricity moves in positive $\mathrm{x}$ direction.

Whereas Fig. 5 represents a comparison between the radial profile for the time average static pressure, tangential and axial velocities at the nine different sections for case (0) and case (5) where we move the eccentricities in positive $\mathrm{x}$ and $\mathrm{y}$ directions.

It is clear that the static pressure for all the cases is nearly the same at different sections near the wall while its effects slightly vary in the central region. 
Table 5: The position of different plotting sections

\begin{tabular}{|c|c|c|c|}
\hline Section & Z/D & & \\
\hline $\mathrm{S} 1$ & 2.75 & $L$ & \\
\hline $\mathrm{S} 2$ & 2.5 & \begin{tabular}{|l}
57 \\
56 \\
\end{tabular} & \\
\hline S3 & 2.25 & \begin{tabular}{|l}
53 \\
54 \\
\end{tabular} & $I^{-}$ \\
\hline S4 & 2 & \begin{tabular}{|l|}
52 \\
59
\end{tabular} & \\
\hline S5 & 1.75 & & \\
\hline S6 & 1.5 & & \\
\hline S7 & 1.25 & $B C$ & \\
\hline S8 & 1 & $D$ & \\
\hline S9 & 0.75 & & \\
\hline
\end{tabular}

$\mathrm{Z}$ is measured from the top of the inlet section.

Figures 4 and 5 show that the static pressure has the $\mathrm{V}$-shape for all the sections inside the cyclone. Where the pressure increases toward the cyclone wall and decreases in the central region. The negative pressure in the central region motivate the settling of the particles in the dustbin.

Tangential velocity exhibits the Rankin velocity profile Figs 4-5. It increases from the wall to half the distance toward the center then it starts to decrease again in the central region. It is clear from Figures 4, 5 that the tangential velocities are nearly the same at different sections for cases 0 and 3 while it differs in the central region (deformation appear in the central region) when moving the eccentricities in both $\mathrm{X}$ and $\mathrm{Y}$ directions (cases 5).

The axial velocity exhibits the inverted $\mathrm{W}$ shape for all cases, as shown in Figs. 4 and 5. However, the deformation appears clearer when moving the eccentricities in both $\mathrm{x}$ and $\mathrm{y}$ directions as shown in Fig. 5. 

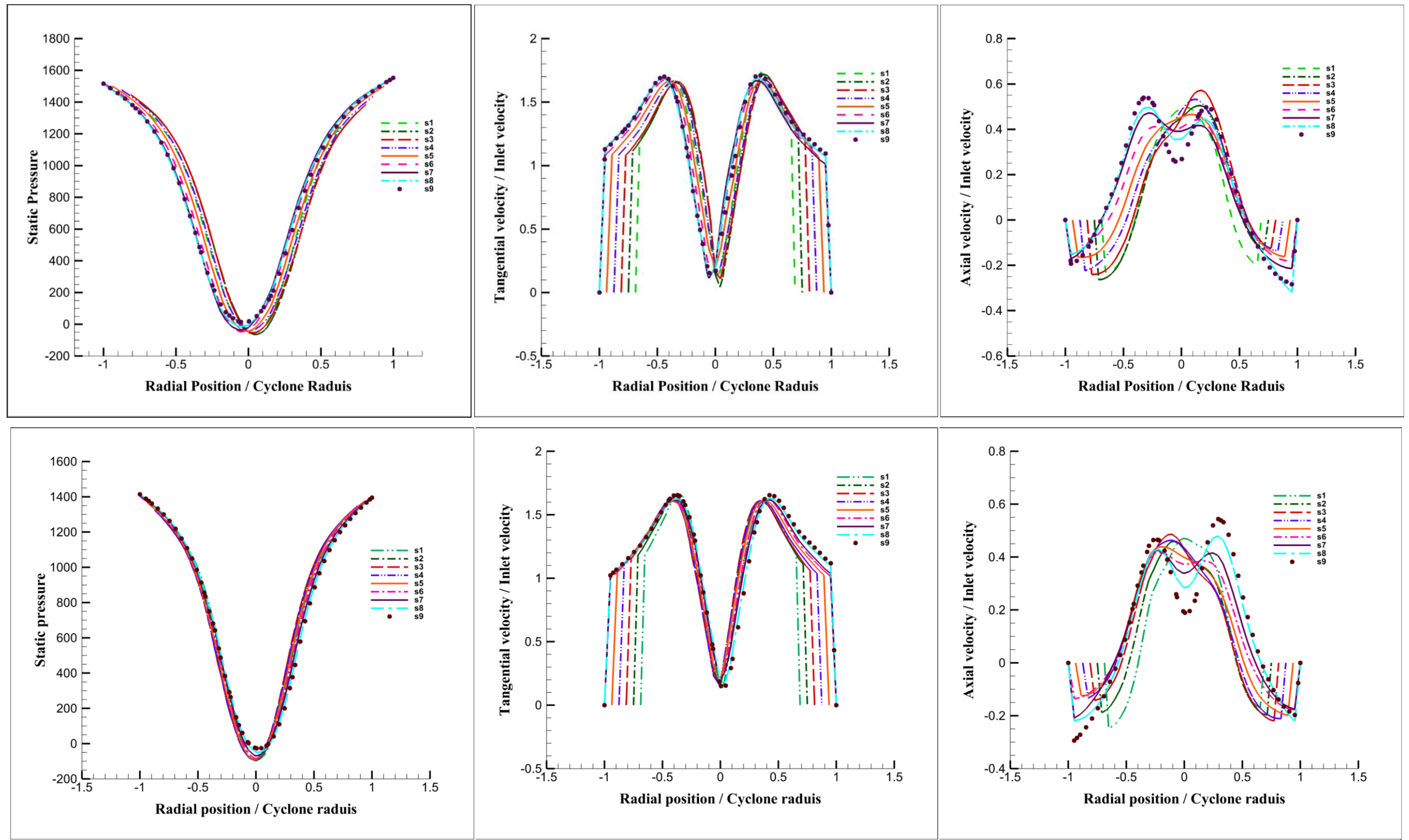

Figure 4: The radial profile for the time average Static pressure, tangential and axial velocities at different sections for case 0 and case 3 respectively. 

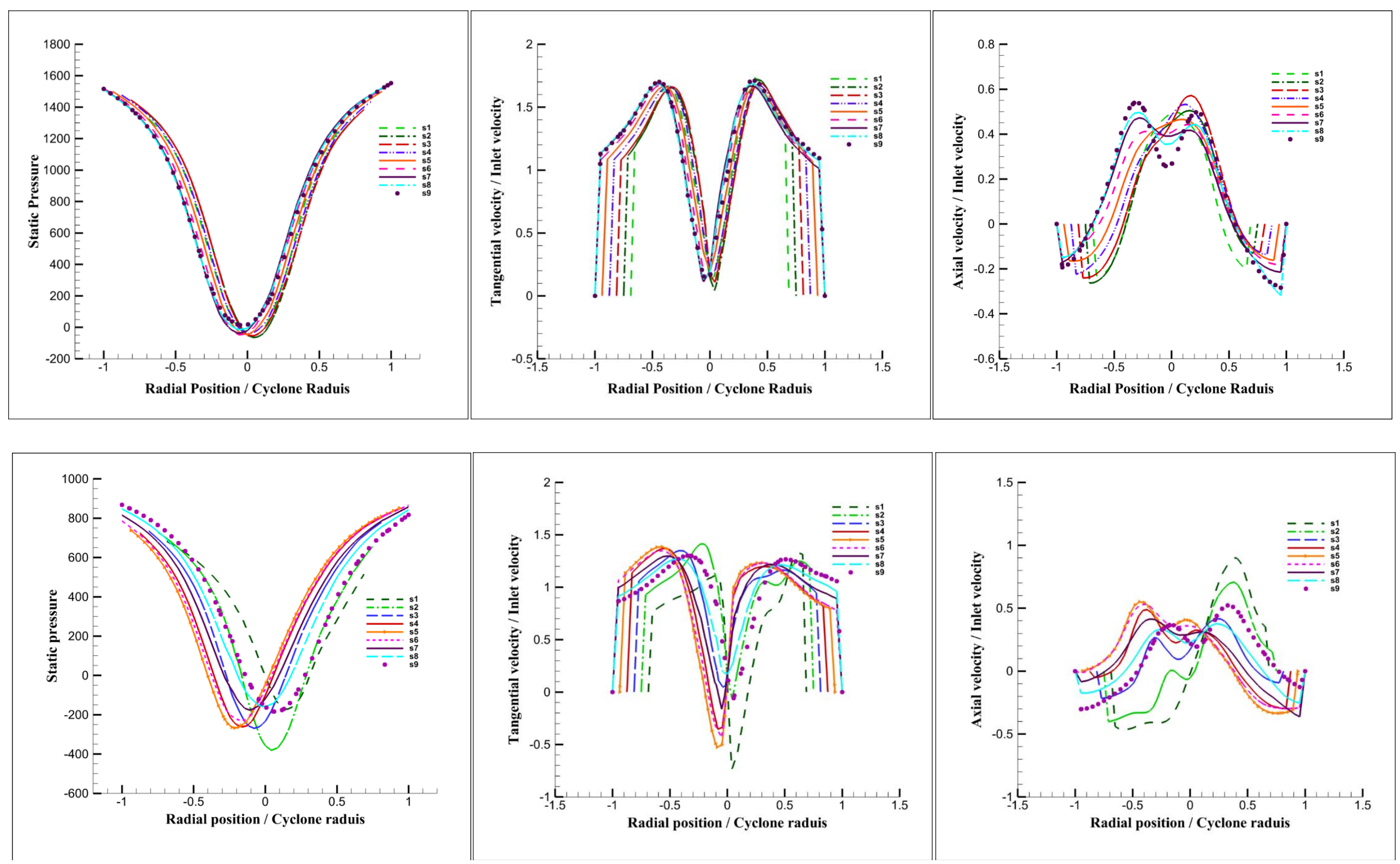

Figure 5: The radial profile for the time average Static pressure, tangential and axial velocities at different sections for case 0 and case 5 respectively. 


\subsection{The flow pattern:}

Figure 6 shows the contour plots for the time average static pressure, tangential and axial velocities for case 0 to case 4 at section $y=0$, while Fig. 7 shows the contour plots for the time average static pressure, tangential and axial velocities for case 0 and cases 5 to 8 at section $y=0$. It is shown that the eccentricity of the vortex finder reduces the static pressure but it also decreases the tangential velocity which will reflect in decreasing the cyclone collection efficiency.

Table (6) shows the pressure drop for the nine cases; it is obvious that case (5) and case (8) achieve the lowest pressure drop opposed to other cases. Moving the eccentricities toward the inlet section is more efficient in reducing the cyclone pressure drop.

Table 6: The pressure drop for the nine cases

\begin{tabular}{|l|l|l|l|l|l|l|l|l|l|}
\hline Cases & $\mathbf{0}$ & $\mathbf{1}$ & $\mathbf{2}$ & $\mathbf{3}$ & $\mathbf{4}$ & $\mathbf{5}$ & $\mathbf{6}$ & $\mathbf{7}$ & $\mathbf{8}$ \\
\hline $\begin{array}{l}\text { Pressure } \\
\text { drop (Pa) }\end{array}$ & 1131.3 & 1039.3 & 1168.9 & 1042.1 & 1161.4 & 778.2 & 1033.3 & 1132.3 & 924.34 \\
\hline $\begin{array}{l}\text { Euler } \\
\text { number }\end{array}$ & 5.7 & 5.2 & 5.85 & 5.21 & 5.8 & 3.89 & 5.17 & 5.66 & 4.62 \\
\hline
\end{tabular}

To show the effect of the vortex finder eccentricities on the static pressure and the tangential and axial velocities profiles, the static pressure and the tangential and axial velocities profiles are drawn for the nine cyclones at section S9 in Figure (9).

The static pressure is slightly decreased for the first four cases where the eccentricity is moved in one direction while the static pressure for cases 5 to 8 decreased more clearly where the eccentricities is moved in two directions as shown in Figs.8 and 9.It is also noticed that some curve is not symmetric around the centerline as moving the vortex finder directly affect the flow pattern inside the cyclone. The tangential velocity for the first four cases is so closed while there is clear reduction in the tangential velocities for cases 5 to 8 compared to case 0 .

The axial velocity has the shape of inverted $\mathrm{W}$ as shown in Figs. 8 and 9, it is clear that the $\mathrm{w}$ shape is not symmetric around the cyclone centerline due to eccentricities of the vortex finder, it is obvious from the graph that the axial velocity is higher in positive position then it reduces in negative position of the axis and vice versa (compared to case 0 without eccentricity). 


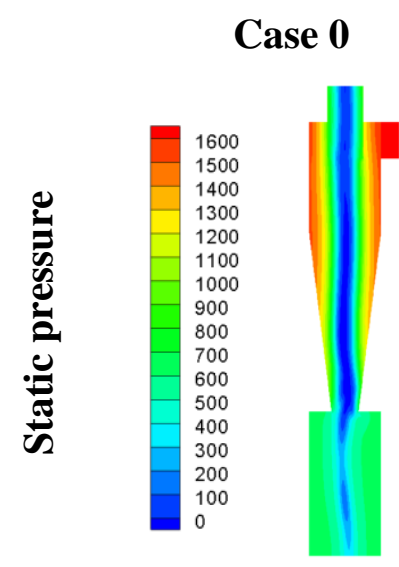

Case 1
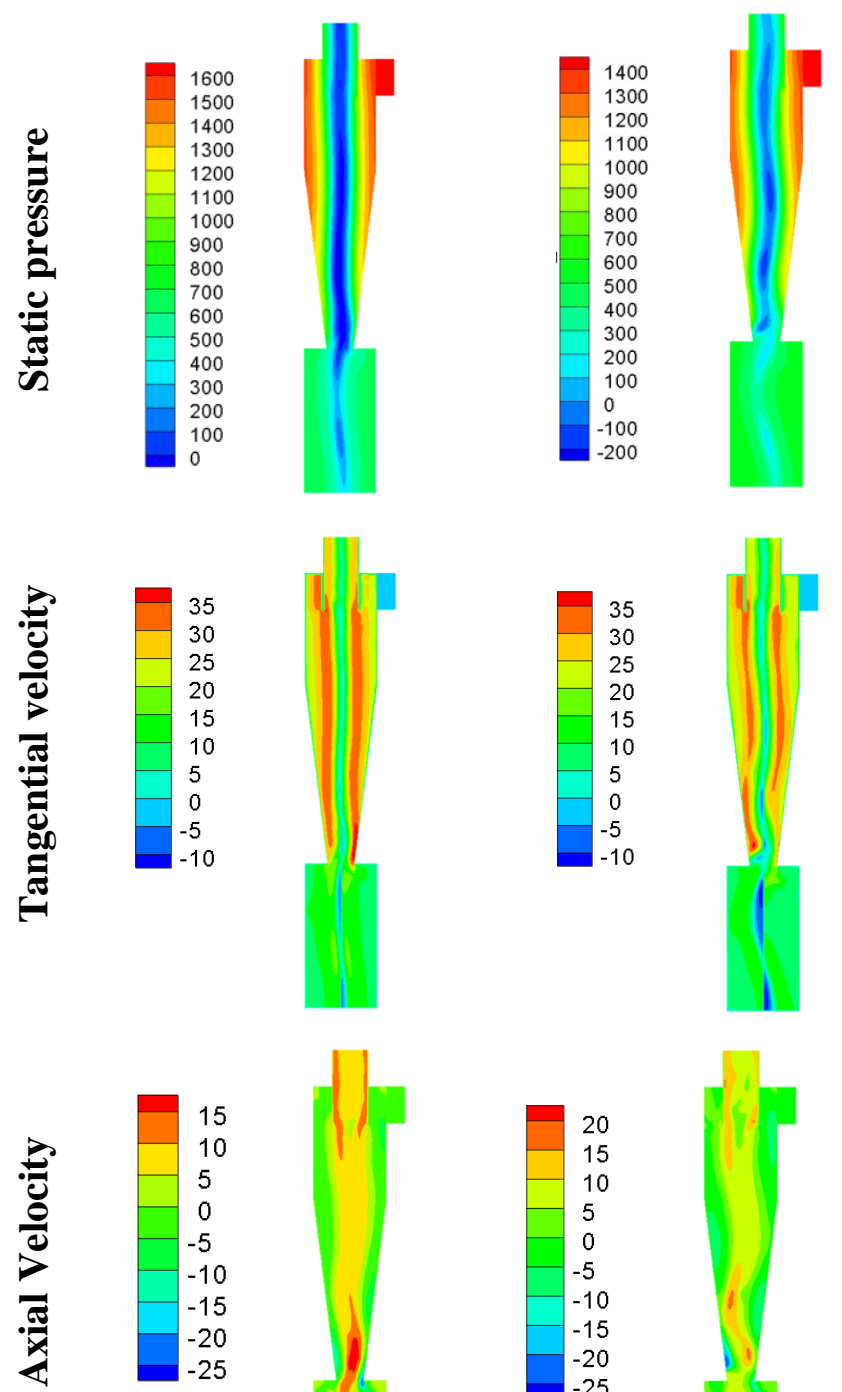
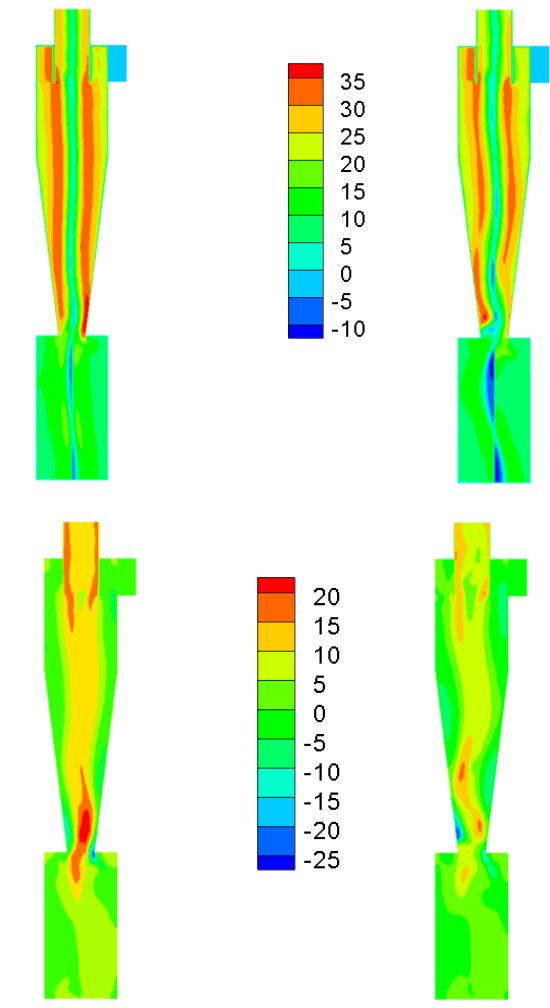

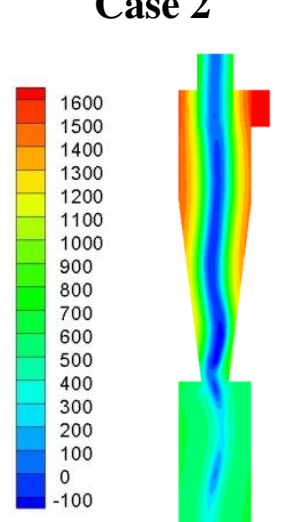

Case 3
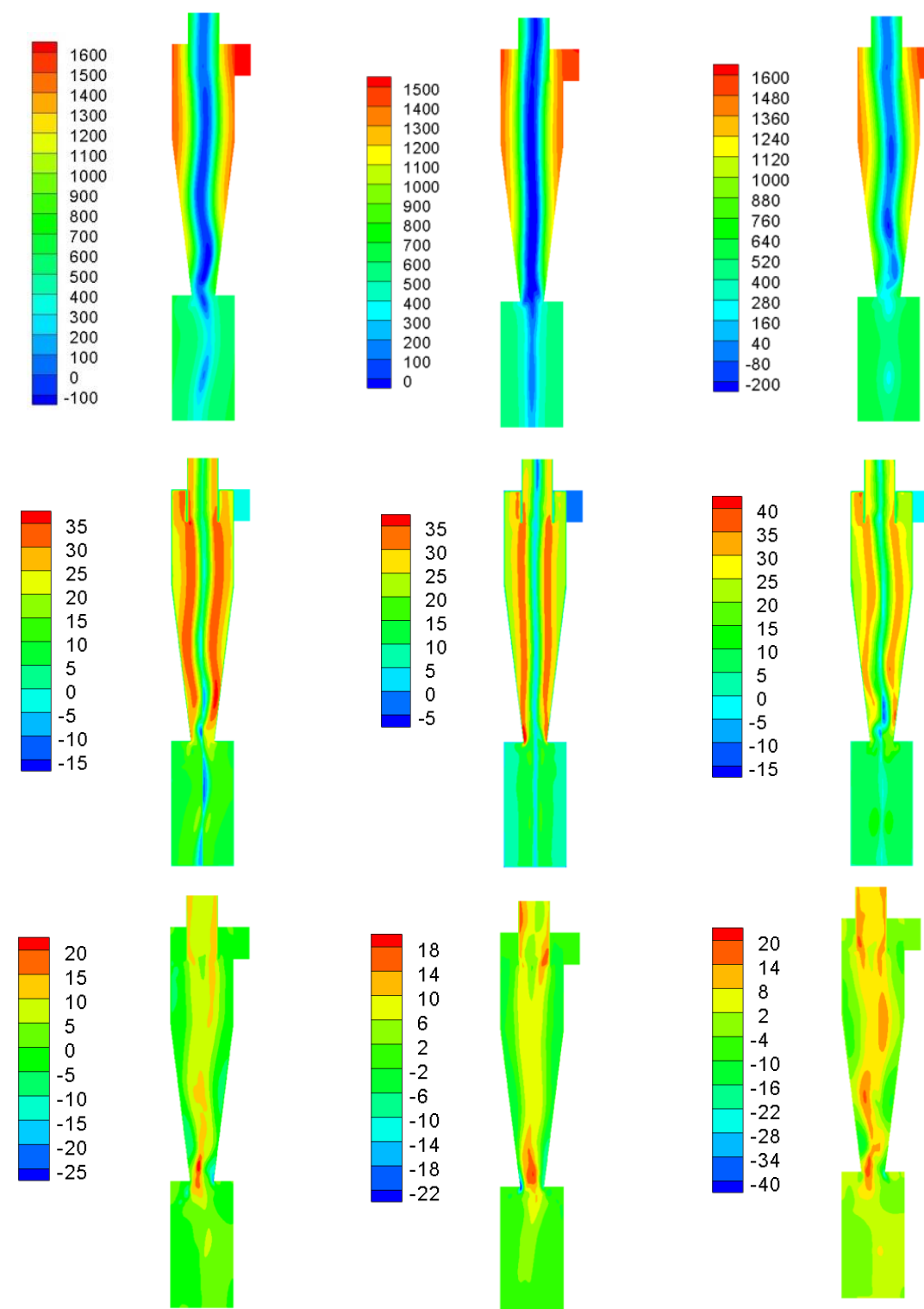

Figure 6: Contours plot for the time average static pressure [N/m2], Tangential velocity [m/s] and axial velocity [m/s] from top to bottom respectively at section $Y=0, S 9(Z=1076.25 \mathrm{~mm}$ measured from the cyclone bottom $)$ 
Case 0
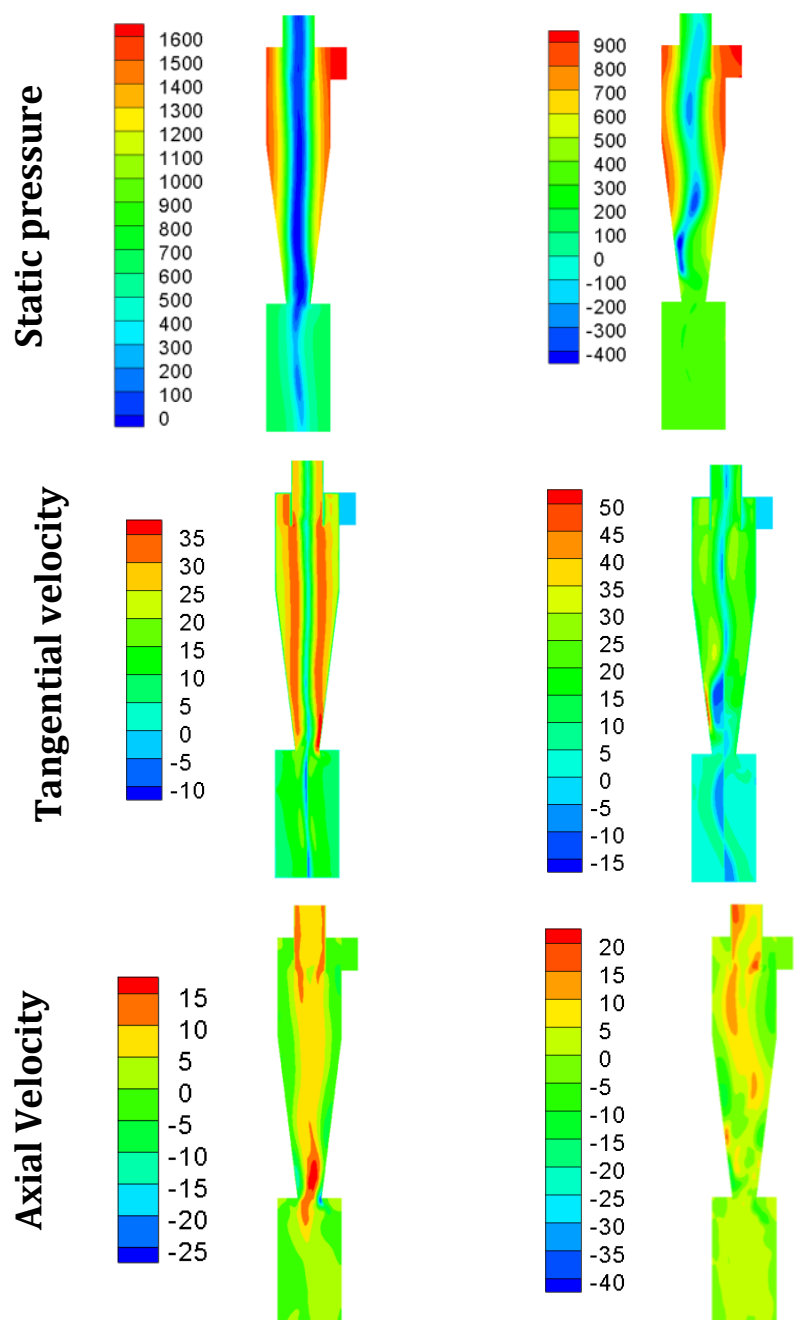

Case 6
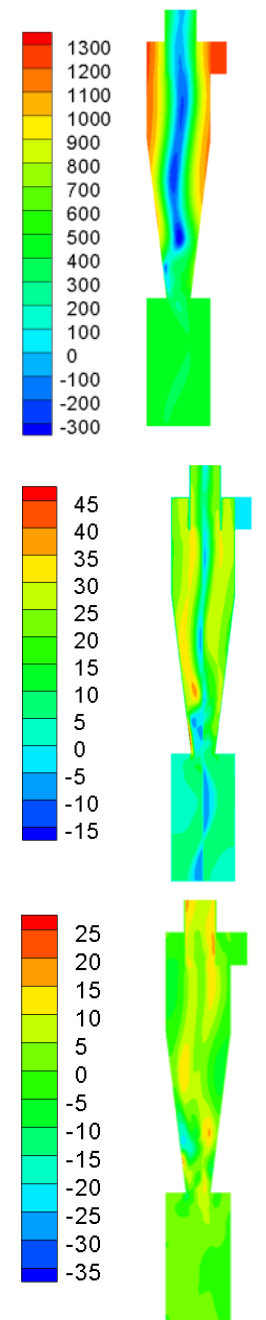

Case 7

Case 8
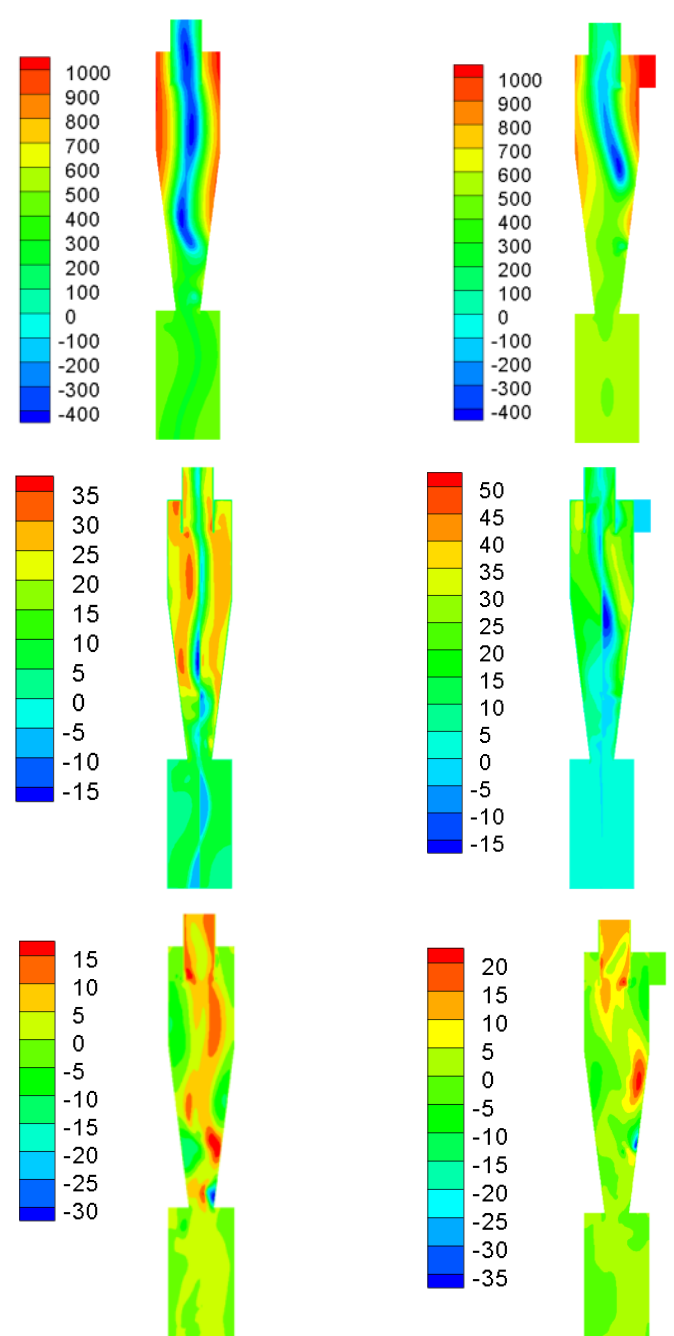

Figure 7: Contours plot for the time average static pressure [N/m2], Tangential velocity [m/s] and axial velocity [m/s] from top to bottom respectively at section $\mathrm{Y}=0, \mathrm{~S} 9(\mathrm{Z}=1076.25 \mathrm{~mm}$ from the cyclone bottom) 

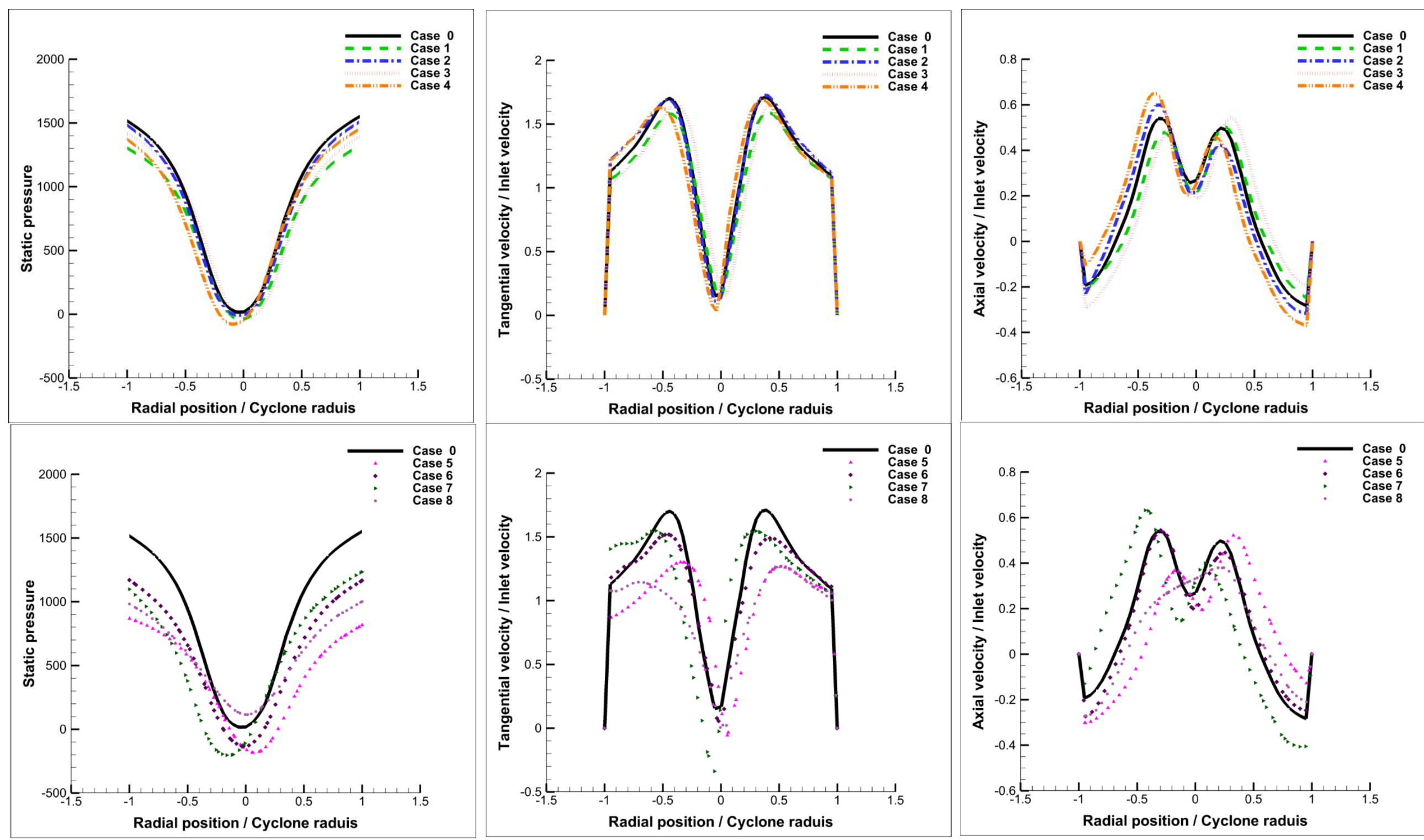

Figure 8: Comparison between the time average static pressure, tangential and axial velocities at section $\mathrm{S9}$ for the first and the last four cases compared to case 0 

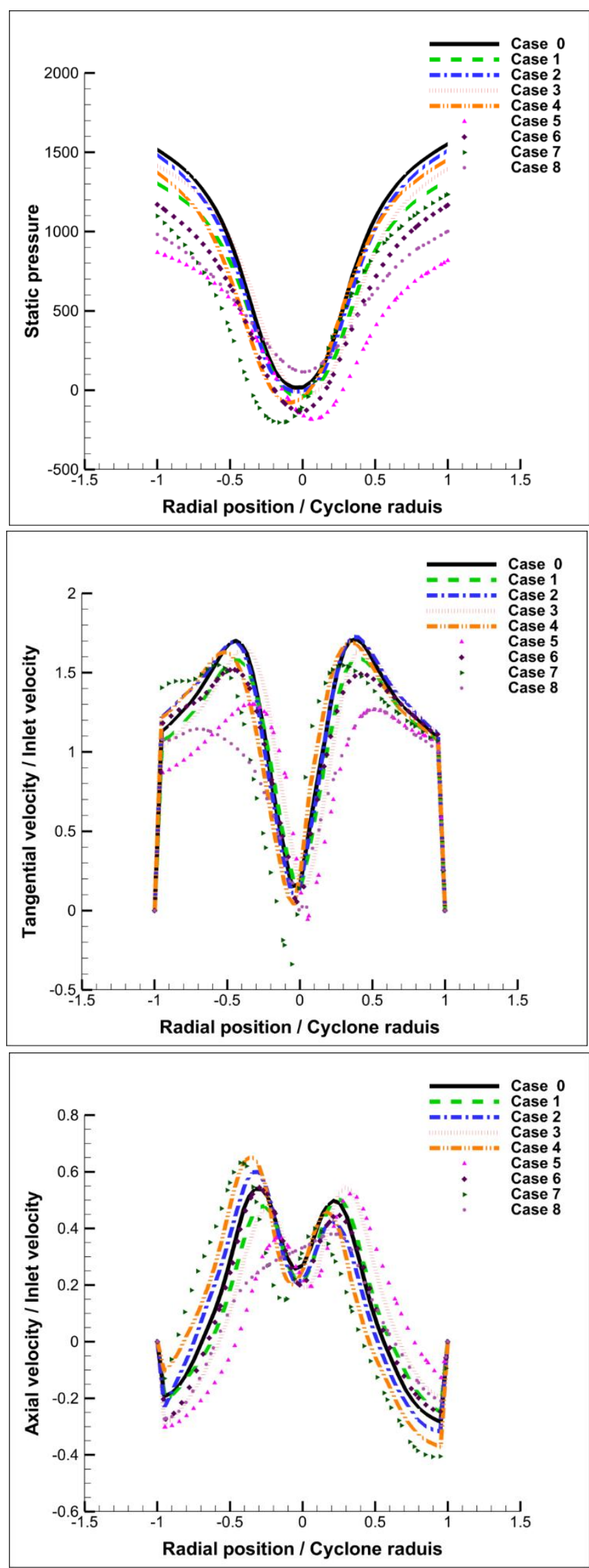

Figure 9: Comparison between the time average static pressure, tangential and axial velocities at section $\mathrm{S} 9$ for the nine cases 


\subsection{The cyclone performance:}

For the first four cases (1 to 4), moving the eccentricity in positive $\mathrm{x}$ or $\mathrm{y}$ direction (toward the inlet section) reduces pressure drop with $8 \%$ approximately. While moving the eccentricity in negative $\mathrm{x}$ or $\mathrm{y}$ direction increases pressure drop by 2.5 $3 \%$ as shown in Table (6). However, moving eccentricity in both directions $\mathrm{x}$ and $\mathrm{y}$ is considered more effective. As moving the eccentricity in positive y direction with positive and negative $\mathrm{x}$ toward the cyclone inlet, reduce pressure drop from 18 to $31 \%$ such as in cases 5 and 8 respectively.

\section{Conclusions}

Nine cyclones have been used to study the effect of the vortex finder eccentricity on the cyclone performance by using the Reynolds stress turbulent model. The following conclusions have been obtained:

- Increasing the vortex finder eccentricity reduces cyclone pressure drop from 9 to $30 \%$ though it also reduces the tangential velocity 5 to $22 \%$ with respect to the concentric case that in turn reduces the cyclone collection efficiency.

- It is more effective to move the vortex finder eccentricity in two directions than that in one direction only.

- Moving the eccentricity toward the inlet section achieves the lowest pressure drop but it also lowers the maximum velocity.

\section{References}

Lozia, D.L., Leith, D. (1989). Effect of cyclone dimensions on gas flow pattern and collection efficiency. Aerosol Science and Technology. 10(3):491-500.

Kim, J. C. \& Lee, K. W. (1990). Experimental study of particle collection by small cyclones, Aerosol Science and Technology, 12:4, 1003-1015.

Moore, M.E. and McFarland, A.R. (1990). Design of Stairmand-Type Sampling cyclones. American Industrial Hygiene Association journal. 51(3): 151-159.

Overcamp, T. J. and Scarlett, S. E. (1993). Effect of Reynolds Number on the Stokes Number of Cyclones. Aerosol Science and Technology. 19(3): 362-370.

Moore, M.E. and McFarland, A.R. (1993). Performance modeling of single- inlet aerosol sampling cyclones. Environmental Science and Technology. 27: 18421848.

Zhu, Y., Lee, K. W. (1999) Experimental study on small cyclones operating at high flowrates. Aerosol Science and Technology. 30 (10): 1303-1315.

Lian-Ze Wang \& Long Ye. (1999). Reducing pressure drop in cyclones by a stick. Aerosol science and Technology. 3.1:2-3,187-193. 
Hoekstra, A. J., Derksen, J.J., Van Den Akker, H.E.A. (1999). An experimental and numerical study of turbulent swirling flow in gas cyclones. Chemical Engineering science. $54: 2055$ - 2065.

Hoekstra, A. J. (2000). Gas flow field and collection efficiency of cyclone separators. Ph.D. thesis, Technical University Delft.

Lim, K.S., Kim, H.S., Lee, K.W. (2004). Characteristics of the collection efficiency for a cyclone with different vortex finder shapes. Journal of Aerosol science 35(6): 743-54.

Karagoz, I. and Avci, A. (2005). Modelling of the pressure drop in tangential inlet Cyclone separators. Aerosol Science and Technology 39(9): 857-865.

Chuah, T.G., Gimbun, J., Thomas, S. Y. (2006). A CFD study of the effect of cone dimensions on sampling aerocyclones performance and hydrodynamics. Powder Technology 162 (2006) $126-132$.

Dobrowolski, B., Skulska, J., Wydrych, J. (2008). Numerical Modelling of erosion wear of components of cyclone separators. Research Gate 259500597.

Elsayed, K., Lacor, C. (2010). The effect of the vortex finder diameter on cyclone separator performance and flow field. V European conference on computational fluid dynamics.

Elsayed, K., Lacor, C. (2010). Optimization of the cyclone separator geometry for minimum pressure drop using mathematical models and CFD simulations. Chemical Engineering Science 65:6048-6058.

Elsayed, K., Lacor, C. (2011). The effect of cyclone inlet dimensions on the flow pattern and performance. Applied Mathematical Modeling 35:1952-1968.

Elsayed, K., Lacor, C. (2011). Numerical modeling of the flow field and performance in cyclones of different cone-tip diameters. Computers \& Fluids 51:48-59.

Elsayed, K. (2011). Analysis and optimization of cyclone separators geometry using RANS and LES Methodologies. Ph.D. thesis, Vrije University Brussel.

Elsayed, K., Lacor, C. (2012). The effect of the dust outlet geometry on the performance and hydrodynamics of gas cyclones. Computers \& Fluids 68:134147.

Elsayed, K., Lacor, C. (2012). Modeling and Pareto optimization of the gas cyclone separator performance using RBF type artificial neural networks and genetic algorithms. Power Technology 217:84-99.

Cernecky, J., Plandorova, K. (2013). The effect of the introduction of an exit tube on the separation efficiency in a cyclone. Brazilian Journal of Chemical Engineer 30(3): 627-641. 
Elsayed, K., Lacor, C. (2013). The effect of cyclone vortex finder dimensions on the flow pattern and performance using LES. Computers \& Fluids 71:224-239. El Batsh, M. (2013). Improving cyclone performance by proper selection of the exit pipe. Applied Mathematical Modeling 37:5286-5303.

Reddy Dere, B. R., Mahesh Babu, G., Divy sree,A., Rajiv Rao, S.(2014). Design and analysis of cyclone separator. International journal of engineering research and technology 3(8): 2278-0181.

Liu, L., Dou, H. S., Chen, X. P., Zhang, H. Z. (2015) Analysis of vortex flow in a cyclone separators based on the energy gradient theory. Materials Science and Engineering 72:042037.

Brar, L. S., Sharma, R. P., Dwivedi, R. (2015). Effect of Vortex finder diameter on flow field and collection efficiency of cyclone separators. Particulate Science and Technology: An international journal 33(1): 34-40.

Funk, P. A., (2015). Reducing cyclone pressure drop with evases. Powder Technology 272:276-281.

Parvaz, F., Hosseini, S. H., Ahmadi, G., Elsayed, K. (2017). Impacts of the vortex finder eccentricity on the flow pattern and performance of a gas cyclone. Separation and Purification Tech. 187:1-13.

Parvaz, F., Hosseini, S. H., Elsayed, K., Ahmadi, G. (2018). Numerical investigation of effects of inner cone on flow field, performance and erosion rate of cyclone separators. Separation and Purification Tech. 201:223-237.

Brar, L. S., Elsayed, K. (2018). Analysis and optimization of cyclone separators with eccentric vortex finders using large eddy simulation and artificial neural network. Separation and Purification Technology10.1016. 